\title{
Polyphenol release in Borlotti beans (Phaseolus vulgaris) during cooking, soaking, simulated digestion and acid hydrolysis
}

\author{
L. Perez-Hernandez, M. Morgan, C. Bosch and C. Orfila \\ School of Food Science and Nutrition, University of Leeds, Leeds, LS2 9JT, UK
}

Polyphenols present in beans have been associated with the putative health benefits of this legume ${ }^{(1)}$. However, the bean matrix may have an impact on the bioaccessibility and bioavailability of polyphenols ${ }^{(2)}$. There is limited knowledge on the release of polyphenols from the matrix during starch and protein digestion. The aim of this study was to quantify and characterise the polyphenols released during domestic food preparation and simulated intestinal digestion of Borlotti beans. The polyphenols remaining in the fibre residue fraction were also quantified. the polyphenols released during domestic food preparation and simulated intestinal digestion of Borlotti beans. The polyphenols remaining in the fibre residue fraction were also quantified.

Beans $(25 \mathrm{~g})$ were soaked overnight in water $(100 \mathrm{~mL})$ and drained. The soaked beans were then boiled in water $(100 \mathrm{~mL})$ for $1 \mathrm{~h}$ and then drained again. Cooked beans were homogenised and digested using an optimized simulated digestion method using porcine pancreatic $\alpha$-amylase $(250 \mathrm{U})$, amyloglucosidase $(80 \mathrm{U})$, and protease $(30 \mathrm{U})$ in sodium maleate $(50 \mathrm{mM})$ with CaCl $\mathrm{Cl}_{2}(2 \mathrm{mM})$ buffer. The remaining undigested residue was hydrolyzed using $1 \mathrm{M} \mathrm{HCl}$ for $1 \mathrm{~h}$. Total polyphenols (TPP) released during each stage were determined using the Folin Ciocalteu assay and expressed as gallic acid equivalents (GAE). Results are shown in Table 1.

Enzymatic digestion resulted in the highest amount of extractable polyphenols compared to cooking, soaking and fibre residue. It was also observed that a higher amount of polyphenols were released after starch digestion than after protein digestion. But the highest release was observed during simultaneous digestion of starch and protein.

Table 1. Total polyphenol content (TTP) of fractions released during soaking, cooking, enzymatic digestion and acid hydrolysis.

\begin{tabular}{lr}
\hline & \multicolumn{1}{c}{ TPP released (mg GAE/ g cooked sample) } \\
\cline { 2 - 3 } Process/fraction & Mean \\
\hline Soaking & $1 \cdot 95$ \\
Cooking & $2 \cdot 22$ \\
Protein digestion & $6 \cdot 54$ \\
Starch digestion & $30 \cdot 78$ \\
Protein and starch digestion & $40 \cdot 42$ \\
1N HCl digestion of undigested residue & $4 \cdot 15$ \\
\hline
\end{tabular}

Values are means for three independent experiments. Mean values were significantly different between samples (ANOVA, followed by Tukey test): *P<0.05.

Results indicate that most of the polyphenols in Borlotti beans are retained during soaking and cooking and released upon digestion of the starch and protein matrix. The polyphenol content in the undigested residue would be available for fermentation by the microbiota. Further experiments are required to identify the polyphenols present in each fraction and evaluate the possible health benefits exerted by the polyphenols present in both digestion and fibre residue fractions.

1. Oomah BD, Tiger N, Olson M et al. (2006) Plant Foods Hum Nutr 61, 86-92.

2. Jakobek L (2015) Food Chem 175, 556-67. 